\title{
Glycemic Control, Medication Use and Obesity among Patients with Type 2 Diabetes Mellitus Presenting to an Endocrinology Clinic during the War in Yemen.
}

\section{A Three-Year Retrospective Study}

\author{
Butheinah A Al-Sharafi' ${ }^{*}$, Mohammed A Algoby ${ }^{2}$, and Khalil Salem ${ }^{3}$ \\ ${ }^{1}$ Associate Professor Department of Medicine, Sana'a University, Sana'a, Yemen \\ ${ }^{2}$ Assistant Professor Department of Medicine, Sana'a University, Sana'a, Yemen \\ ${ }^{3}$ Department of medicine, University of Science and technology hospital, Sana'a, Yemen
}

*Corresponding author: Butheinah A Al-Sharafi, Associate Professor Department of Medicine, Sana’a University, Sana'a, Yemen, Tel: +967 733733573; E-mail: balsharafi@hotmail.com

Received: 12 Jun, 2020 | Accepted: 23 Jun, 2020 | Published: 29 Jun, 2020

Citation: Al-Sharafi BA, Algoby MA, Salem K (2020) Glycemic Control, Medication Use and Obesity among Patients with Type 2 Diabetes Mellitus Presenting to an Endocrinology Clinic during the War in Yemen. A Three-Year Retrospective Study. J Diab Res Ther 6(2): dx.doi. org/10.16966/2380-5544.152

Copyright: (c) 2020 Al-Sharafi BA, et al. This is an open-access article distributed under the terms of the Creative Commons Attribution License, which permits unrestricted use, distribution, and reproduction in any medium, provided the original author and source are credited.

\begin{abstract}
Background and Aims: The war in Yemen caused the already weak health system in the country to decline. We conducted a 3-year retrospective chart review on patients with type 2 Diabetes Mellitus (DM) attending an endocrinology center for the first time during the war, most of the patients were treated by internists and in government hospitals prior to presentation and only a small amount had seen a specialist prior to presentation.

Patients and methods: A total of 4261 charts (2005 males and 2256 females) were reviewed on all patients with type 2 DM attending an endocrinology center for the first time from Jan 2017-Dec 2019. The age, age at onset of diabetes, BMI, medications at presentation were documented in all patients. The HBA1c was documented in only 4031 of the patients' charts.

Results: The mean age of the patients was 51.2 (SD 12.4) and the mean age at diagnosis was 44.6 years (SD 11.5). The mean duration of diabetes was 6.6 (SD 6.6) years. The mean HBA1c was 9.7 (SD 2.7) In 58.4\% of the patients the HBA1c was $>9 \%$ and only $14.4 \%$ had an HBA1C $<7 \%$. The mean BMI in females was 28.3 (SD 5.4) in comparison to males 25.8 (SD 4.4). Obesity was higher in females (33.9\%) than in males (15.6\%) OR 2.78 ( $p$-value $<0.001$ ). The most common medications used were metformin+sulfonylurea (met+sulf) combination in $31.4 \%$ of the patients followed by sulfonylureas (sulf) in $13.2 \%$, metformin (met) $13 \%$ and insulin $12.8 \%, 18.8 \%$ weren't on any medications and only $11.1 \%$ were on any other combination of medications. The patients on met and on 4 oral agents showed a significantly lower HBA1c than those not on medications whereas patients on other medications did not have significant lowering of the HBA1c when compared with those not on medications. When compared to a previous study done in the same center 2007-2011 there was a significant increase in obesity among males.
\end{abstract}

Conclusion: Patients with type 2 DM presenting to an endocrinology clinic during the war in Yemen showed poor control, little use of newer available medications and less obesity among males when compared to females.

Keywords: War in Yemen; Type 2 DM; Primary Care setting; BMI; Obesity; HBA1c; Glycemic control

\section{Introduction}

The war in Yemen which started in March 2015 has caused the health system to decline and has resulted in a humanitarian disaster [1]. This caused an increase burden on patients with diabetes mellitus [2]. Due to the small number of diabetologists and endocrinologists in the country the majority of patients are followed by internists, general practitioners and some patients buy medications directly from a pharmacy or as advised by a friend without seeing a physician and present late with complications. Many patients during the war had lost their income [1] and depend on medications supplied to them by hospitals and health care centers. Factors that limit the standard interventions in diseases in low income countries include political instability, poor health literacy, limited facilities, poor drug supply, and absence of health insurance for the majority of patients [3]. All of these factors are present in Yemen and affect the treatment of diabetic patients. Studies in other countries have shown poor control of diabetes followed in primary care centers [4-7].

This study was a chart review on all patients with type $2 \mathrm{DM}$ presenting to an endocrinology center for the first time over a 3-year period from January 2017 through December 2019. The majority of the patients presenting to us had been treated in hospitals or by internists or general practitioners only a very small number had been 
seen by an endocrinologist at some time. We reviewed the medications that the patients used at presentation, the HBAlc, BMI, age, duration of illness and age at onset of DM. We also compared the data on the BMI, HBA1c, and age to a previous database done from 2007-2011 in the same center.

\section{Patients and Methods}

We conducted a retrospective chart review on all patients with type 2 diabetes presenting to a specialized endocrinology clinic in Sana'a Yemen, aged 20 years and above during the period January $1^{\text {st }}$ 2017-Dec 31st 2019. A total of 4261 patients presented for the first time during the study-period. The following data were collected from the medical records: Gender, age at presentation and at diagnosis of diabetes, duration of diabetes, weight, height, BMI, HBA1c at presentation and medications at presentation. The age at presentation in years and age at diagnosis was divided into the following categories: $<25$ years, $25-34,35-44,45-54,55-64, \geq 65$. The duration of diabetes in years was categorized as follows: $<1,1-4.9$, $5-9.9,10-14.9, \geq 15$. The medications were divided into 16 different categories; no medications, sulf, met, Thiazolidinediones (TZD), dipeptidyl 4 inhibitors (DPP-4) Sodium-glucose transporter-2 inhibitors (SGLT-2), insulin, metformin+sulfonylureas, met+TZD, met+DPP-4 inhibitors, sulfonylureas+TZD, metformin+sulf+TZD, met+sulf+DPP-4, 4 oral agents, oral agents plus insulin, met+sulf+SGLT-2. The HBAlc (\%) was divided into $<7,7-8.9, \geq 9$. The weight and height were documented from the chart and the BMI was calculated $\left(\mathrm{Kg} / \mathrm{m}^{2}\right)$ and categorized to $<18.5,18.5-24.99,25-29.99$, 30-34.99, 35-39.99 and $\geq 40$.

The study was approved by the ethical committee at the University of Science and Technology Hospital.

\section{Statistical Analysis}

The data was analyzed using SPSS 23 (Statistical Package for the Social Sciences, version 23 IBM, Armonk, NY, USA) and presented using tables. Qualitative variables were expressed as frequencies and percentages. The quantitative variables were expressed as means and Standard Deviation (SD) as the data was normally distributed.

Chi-square test was used to show the significance of association between the outcome and the risk factors and Odds Ratios (OR) and 95\% Confidence Iintervals (CIs) was calculated to measure the risk using logistic regression. Independent $\mathrm{T}$-test was used to determine the differences in the mean score between the groups and the normally-distributed quantitative variables. P-value of less than 0.05 was considered statistically significant.

\section{Results}

General characteristics of the patients can be seen in table 1. The mean age of the patients presenting to the clinic was 51.2 years (SD 12.4), males slightly younger with a mean age 50.4 years (SD 13.3) vs 52 years (SD 11.4) in females. The mean age at diagnosis was 43.9 years (SD 12.2) among males vs. 45.2 (SD 10.7) in females and the mean duration of diabetes 6.6 years.

The mean BMI in males was $25.8 \mathrm{~kg} / \mathrm{m}^{2}$ (SD 4.4) and in females 28.3 (SD 5.4). Overall a total of $25.3 \%$ of the patients were obese (15.5\% of males and $33.8 \%$ of the females).

The majority of the patients presenting to the center had uncontrolled DM with only $14.4 \%$ having an HBA1c $<7 \%, 27.2$ percent of the patients had an HBAlc of 7-8.9 and 58.4\% had an HBA1c $>9 \%$. The number of patients that didn't have an HBA1c recorded in the chart was 248 either due to not returning to the clinic after having the test or it was not documented.

The majority of the patients $81.2 \%(\mathrm{~N}=3462)$ were already on medications at presentation and $18.8 \%(\mathrm{~N}=799)$ were not on medications.

The distribution of the different medications on presentation can be seen in table 2 .

The largest group of patients $31.1 \%(\mathrm{~N}=1336)$ were on a sulf + met combination, followed by sulf $13.2 \%(\mathrm{~N}=564)$, met $13 \%(\mathrm{~N}=553)$ and then insulin $12.8 \%(\mathrm{~N}=544)$ and with $18.8 \%$ not on any medications. The remaining $11.1 \%$ of the patients were on any other medication combination with only 2 patients on 4 oral agents.

The majority of patients not on medications were of recent onset (Mean duration of DM 1.6 years (SD 3.1) while those on medications had a mean duration of DM 7.8 years(SD 6.7) p-value $<0.001$.

The prevalence of obesity among females was $33.9 \%$ compared to $15.6 \%$ of male (p-value $<0.001$, OR 2.78 ). Patients with type $2 \mathrm{DM}$ in the age groups (35-44, 45- 54 and 55- 64 years) were more likely to be obese than others and this was statistically significant ( $\mathrm{p}$-value 0.010 , 0.002 and 0.010 respectively). This can be seen in table 3 . Furthermore, there was a statistical association between the prevalence of obesity and the patients' age at diagnosis of diabetes mellitus in the age groups (25-34, 35- 44, 45-54 and 55-64 years) more than others ( $\mathrm{p}$-value $0.034,0.003,0.001$ and 0.028 respectively) and the highest were in the age group 45 to 54 years. Risk of obesity was significantly higher among those with duration of DM either<one year (26.1\%), 1-4.9 years $(27.1 \%)$ or $5-9.9$ years $(25.5 \%)$ (p-value $0.023,0.007$ and 0.049 respectively). Patients with an $\mathrm{HBA} 1 \mathrm{c}<7 \%$ or between $7-9 \%$ were more likely to be obese than those with hbalc $\geq 9 \%$ (p-value $<0.001$ ).

There was no significant association between obesity and the medications used at presentation in general. However, obesity risk was found to be significantly higher among patients on insulin and oral agents $35.8 \%$, (p-value $<0.001$, OR 1.75).

The majority of the patients had uncontrolled diabetes we compared the different medication groups to the HBAlc this can be seen in table 4. The lowest HBA1c was in the group on 4 oral agents but there were only 2 patients on 4 OHA (p-value 0.058 ). Patients on metformin as a single agent had a mean HBA1c of 8.8 which was significantly lower than those not on medications ( $\mathrm{p}$-value $<0.001$ ), the other groups of medications all had a mean $\mathrm{HBA} 1 \mathrm{c}>9$ with no significant difference when compared to those not on medications.

Among the patients with DM for less than 1 year we found that $20.3 \%$ of the patients were 34 years and younger and the overall mean HBA1c was 9.7 (SD 2.6) similar to the HBA1c of the whole population of the study this can be seen in table 5 .

We compared our data to a previous database done in 2007-2011 in the same center ( $\mathrm{N}=1640$ patients) and found a slight decrease in the age of onset among patients with new onset type $2 \mathrm{DM}$ for less than 1 year but with no significant difference (p-value 0.163 ). The mean age at onset was 44.9 years (SD 12.3) in the current study $v s 45.8$ (SD 11.7) in the previous study.

The BMI in male patients was significantly higher than in the previous study (BMI 25.8 vs 25.42) p-value 0.03 and the HBA1c at presentation was slightly lower among males $9.69 v s 10.07$ previously p-value 0.003 this can be seen in table 6 . 
Table 1: General characteristics of the patients ( $N=4261)$.

\begin{tabular}{|c|c|c|c|c|c|c|c|c|c|c|}
\hline \multicolumn{2}{|c|}{ Variable } & \multicolumn{3}{|c|}{$\begin{array}{c}\text { Male } \\
(n=2005)\end{array}$} & \multicolumn{3}{|c|}{$\begin{array}{l}\text { Female } \\
(n=2256)\end{array}$} & \multicolumn{3}{|c|}{$\begin{array}{c}\text { Total } \\
(n=4261)\end{array}$} \\
\hline Age (year) & & $\begin{array}{l}\text { Mean (SD) } \\
50.4(13.3)\end{array}$ & $\mathbf{N}$ & $\%$ & $\begin{array}{l}\text { Mean (SD) } \\
52.0(11.4)\end{array}$ & $\mathbf{N}$ & $\%$ & $\begin{array}{l}\text { Mean (SD) } \\
51.2(12.4)\end{array}$ & $\mathbf{N}$ & $\%$ \\
\hline & $<25$ & & 28 & 1.4 & & 13 & 0.6 & & 41 & 1.0 \\
\hline & $25-34$ & & 201 & 10.0 & & 132 & 5.9 & & 333 & 7.8 \\
\hline & $35-44$ & & 483 & 24.1 & & 370 & 16.4 & & 853 & 20.0 \\
\hline & $45-54$ & & 495 & 24.7 & & 678 & 30.1 & & 1173 & 27.5 \\
\hline & $55-64$ & & 457 & 22.8 & & 736 & 32.6 & & 1193 & 28.0 \\
\hline & $\geq 65$ & & 341 & 17.0 & & 327 & 14.5 & & 668 & 15.7 \\
\hline \multirow[t]{7}{*}{$\begin{array}{l}\text { Age at } \\
\text { diagnosis year) }\end{array}$} & & $43.9(12.2)$ & & & $45.2(10.7)$ & & & 44.6 (11.5) & & \\
\hline & $<25$ & & 64 & 3.2 & & 46 & 2.0 & & 110 & 2.6 \\
\hline & $25-34$ & & 399 & 19.9 & & 302 & 13.4 & & 701 & 16.5 \\
\hline & $35-44$ & & 651 & 32.5 & & 696 & 30.9 & & 1347 & 31.6 \\
\hline & $45-54$ & & 486 & 24.2 & & 759 & 33.6 & & 1245 & 29.2 \\
\hline & $55-64$ & & 273 & 13.6 & & 348 & 15.4 & & 621 & 14.6 \\
\hline & $\geq 65$ & & 132 & 6.6 & & 105 & 4.7 & & 237 & 5.6 \\
\hline \multirow[t]{6}{*}{$\begin{array}{l}\text { Duration of } \\
\text { DM (years) }\end{array}$} & & $6.5(6.9)$ & & & $6.8(6.4)$ & & & $6.6(6.6)$ & & \\
\hline & $<1$ & & 531 & 26.5 & & 510 & 22.6 & & 1041 & 24.4 \\
\hline & $1-4.9$ & & 471 & 23.5 & & 487 & 21.6 & & 958 & 22.5 \\
\hline & $5-9.9$ & & 397 & 19.8 & & 528 & 23.4 & & 925 & 21.7 \\
\hline & $10-14.9$ & & 319 & 15.9 & & 399 & 17.7 & & 718 & 16.9 \\
\hline & $\geq 15$ & & & & & & & & & \\
\hline Height (m) & & $1.6(0.1)$ & & & $1.5(0.1)$ & & & $1.6(0.1)$ & & \\
\hline Weight (kg) & & $70.1(13.6)$ & & & $65.9(13.1)$ & & & $67.9(13.5)$ & & \\
\hline \multirow[t]{7}{*}{ BMI (kg//m²) } & & $25.8(4.4)$ & & & $28.3(5.4)$ & & & $27.1(5.1)$ & & \\
\hline & $<18.50$ & & 73 & 3.6 & & 48 & 2.1 & & 121 & 2.8 \\
\hline & $18.50-24.99$ & & 821 & 40.9 & & 573 & 25.4 & & 1394 & 32.7 \\
\hline & $25.00-29.99$ & & 799 & 39.9 & & 871 & 38.6 & & 1670 & 39.2 \\
\hline & $30.00-34.99$ & & 251 & 12.5 & & 530 & 23.5 & & 781 & 18.3 \\
\hline & $35.00-39.99$ & & 50 & 2.5 & & 177 & 7.8 & & 227 & 5.3 \\
\hline & $\geq 40$ & & 11 & 0.5 & & 57 & 2.5 & & 68 & 1.6 \\
\hline \multirow[t]{2}{*}{ Obesity } & Yes (BMI $\geq 30)$ & & 312 & 29.0 & & 764 & 71.0 & & 1076 & 25.3 \\
\hline & No $(\mathrm{BMI}<30)$ & & 1693 & 53.2 & & 1492 & 46.8 & & 3185 & 74.7 \\
\hline
\end{tabular}

The prevalence of obesity among the male patients had increased in 2017-2019 from the 2007-2011 study (p-value 0.035) with no significant increase in females ( $\mathrm{p}$-value 0.447 ) this can be seen in table 7. The mean duration of diabetes among those not on medications was 1.6 years in comparison to 7.8 years in patients on medications.

\section{Discussion}

All the charts of patients presenting to a private specialized endocrinology center in Sana'a for the first time 2-5 years after the start of the war in Yemen were reviewed. The majority of the patients were seen in internal medicine or hospital clinics and only a small number had seen an endocrinologist prior to presentation. The mean age of the patients at presentation was 51.2 years this is slightly lower than in another war ridden country as Iraq which had a mean age of patients was 53.78 years [8]. The mean age at diagnosis in patients with type 2 DM less than one year was 44.6 years with no significant difference from a database in the same center from 2007-2011 where the mean age at diagnosis was 45.8 years ( $p$-value 0.163 ).
The mean BMI among males was 25.8 (SD 4.4) and among females was 28.3 (SD 5.4) with $35.5 \%$ of the patients having a $\mathrm{BMI}<25,39.2 \%$ were overweight and $25.3 \%$ of the patients were obese (BMI $\geq 30$ ). When compared to a previous study in the same center there was no significant increase in the prevalence of obesity in females ( $p$-value .447) but in males there was a significant increase in obesity (p-value 0.035) [2]. Other studies from the Arab world show much higher prevalence of obesity among diabetic patients [9]. In Bahrain 31.5\% of diabetics were obese, United Arab Emirates 40\%, Oman 60.1\% and in Saudi Arabia 46\% of diabetics were obese [10-13]. In other Arab countries obesity in diabetes was also higher than Yemen. In Lebanon $36 \%$ and in Palestine $55.6 \%$ of the diabetic patients were obese $[14,15]$. Among the younger patients $<25$ years the rate of obesity was not significantly different from those $\geq 65$ years of age whereas all the other age groups had a significantly higher prevalence of obesity, maybe in the younger patients some had type 1 diabetes and had been misdiagnosed or they had other risk factors. We did not find much increase in weight in diabetic patients over a 6-year period in our

Citation: Al-Sharafi BA, Algoby MA, Salem K (2020) Glycemic Control, Medication Use and Obesity among Patients with Type 2 Diabetes Mellitus Presenting to an Endocrinology Clinic during the War in Yemen. A Three-Year Retrospective Study. J Diab Res Ther 6(2): dx.doi. org/10.16966/2380-5544.152: dx.doi.org/10.16966/2380-5544.152 
Table 2: Hba1c and Medications at presentation.

\begin{tabular}{|c|c|c|c|c|c|c|c|c|c|}
\hline \multirow[t]{2}{*}{ Variable } & \multicolumn{3}{|c|}{$\begin{array}{c}\text { Male } \\
(n=2005)\end{array}$} & \multicolumn{3}{|c|}{$\begin{array}{c}\text { Female } \\
(n=2256)\end{array}$} & \multicolumn{3}{|c|}{$\begin{array}{c}\text { Total } \\
(n=4261)\end{array}$} \\
\hline & Mean (SD) & $\mathbf{N}$ & $\%$ & Mean (SD) & $\mathbf{N}$ & $\%$ & Mean (SD) & $\mathbf{N}$ & $\%$ \\
\hline hba1c* & $9.7(2.9)$ & & & $9.6(2.5)$ & & & $9.7(2.7)$ & & \\
\hline$<7$ & & 253 & 13.5 & & 326 & 15.2 & & 579 & 14.4 \\
\hline $7-8.9$ & & 519 & 27.7 & & 573 & 26.8 & & 1092 & 27.2 \\
\hline$\geq 9$ & & 1102 & 58.8 & & 1240 & 58.0 & & 2342 & 58.4 \\
\hline \multicolumn{10}{|c|}{ Medications at presentation } \\
\hline Yes & & 1563 & 78.0 & & 1899 & 84.2 & & 3462 & 81.2 \\
\hline No & & 442 & 22.0 & & 357 & 15.8 & & 799 & 18.8 \\
\hline \multicolumn{10}{|c|}{ Medications at presentation } \\
\hline No medications & & 442 & 55.3 & & 357 & 44.7 & & 799 & 18.8 \\
\hline Insulin & & 259 & 47.6 & & 285 & 52.4 & & 544 & 12.8 \\
\hline 1 oral agent & & 538 & 46.7 & & 613 & 53.3 & & 1151 & 27.0 \\
\hline$\geq 2$ oral agents & & 680 & 44.3 & & 855 & 55.7 & & 1535 & 36.0 \\
\hline Insulin and oral agents & & 86 & 37.1 & & 146 & 62.9 & & 232 & 5.4 \\
\hline \multicolumn{10}{|c|}{ Medications at presentation } \\
\hline No medication & & 442 & 22.0 & & 357 & 15.8 & & 799 & 18.8 \\
\hline Sulfonylureas & & 262 & 13.1 & & 302 & 13.4 & & 564 & 13.2 \\
\hline Metformin & & 260 & 13.0 & & 293 & 13.0 & & 553 & 13.0 \\
\hline TZD & & 7 & 0.3 & & 12 & 0.5 & & 19 & 0.4 \\
\hline DPP-4 inhibitor & & 7 & 0.3 & & 6 & 0.3 & & 13 & 0.3 \\
\hline SGLT-2 inhibitor & & 2 & 0.1 & & 0 & 0.0 & & 2 & 0.0 \\
\hline Insulin & & 259 & 12.9 & & 285 & 12.6 & & 544 & 12.8 \\
\hline Met+sulf & & 590 & 29.4 & & 746 & 33.1 & & 1336 & 31.4 \\
\hline Met-TZD & & 4 & 0.2 & & 6 & 0.3 & & 10 & 0.2 \\
\hline Met +DDP-4 & & 35 & 1.7 & & 28 & 1.2 & & 63 & 1.5 \\
\hline Sulf+TZD & & 0 & 0.0 & & 3 & 0.1 & & 3 & 0.1 \\
\hline Met+sulf-TZD & & 8 & 0.4 & & 24 & 1.1 & & 32 & 0.8 \\
\hline met+sulf+ DPP-4 & & 41 & 2.0 & & 46 & 2.0 & & 87 & 2.0 \\
\hline 4 oral agents & & 0 & 0.0 & & 2 & 0.1 & & 2 & 0.0 \\
\hline Oral agents+insulin & & 86 & 4.3 & & 146 & 6.5 & & 232 & 5.4 \\
\hline Met+sulf+SGLT-2 & & 2 & 0.1 & & 0 & 0.0 & & 2 & 0.0 \\
\hline
\end{tabular}

Note: * the number of patients that had an HBA1c documented in their charts was 4031 while 248 patients did not have an HBA1c documented at the first visit. TZD=Thiazolidinedione, DPP4=Dipeptidyl peptidase IV, SGLT-2=Selective sodium-glucose transporter-2 inhibitors, Met=Metformin, Sulf=Sulfonylureas.

clinic. The mean BMI in males was 25.42 and this increased to 25.8 (p-value 0.03 ) but with no significant increase in females and overall the mean BMI did not significantly increase, it was previously 26.8 and in our current study it was 27.1 (p-value 0.132 ). We did not see the increased obesity in patients with type $2 \mathrm{DM}$ seen in most countries in the region [9].This may have been affected by the war which has caused an increase in poverty, which in some countries caused a decrease in obesity and diabetes such as occurred in Nauru and Cuba after the economic collapse [16].

The majority of our patients had uncontrolled DM. The mean HBA1c was $9.7 \%$ with $58.4 \%$ having an HBA1c $\geq 9 \%$ and only $14.4 \%$ of the patients had an HBAlc $<7$ and $27.2 \%$ had an HBAlc $7-8.9 \%$ that means $85.6 \%$ of the patients had an HBAlc $>7 \%$. Other countries during war also showed similar poor control with a mean HBA1c 9.3\% in a diabetes center in Iraq [17] and a mean HBA1c 9.4\% among Syrian refugees presenting to a refugee camp in Lebanon [18]. In a previous study done in our center at the start of the war we found that the mean
HBAlc before the war was 7.7\% (SD 1.9) this increased to $8.6 \%$ (SD 2.2) after the war in 111 patients followed up in our center before and shortly after the war started [2].

Other developing countries also showed poor control in the primary care setting similar to Yemen. In Malaysia only $15.6 \%$ had HBA1c $<6.5 \%$ with a mean HBA1c $8.4 \%$ [7]. In Southwest Ethiopia $71 \%$ of ambulatory diabetic patients had uncontrolled fasting blood glucose in one center [4]. Even in developed countries as the USA a study showed that $40.5 \%$ of patients in the primary care setting had an HBA1c $>7 \%$ [19].

Medications used among $31.4 \%$ of the patients was a met+sulf combination with a mean HBA1c of $9.9 \%$ followed by sulf in $13.2 \%$ of the patients as a single agent which is not recommended as first line treatment. The International Diabetes Federation (IDF) recommends sulf as $2^{\text {nd }}$ line treatment and to avoid using glibenclamide [20]. Among our patients the most common sulfonylurea used is glibenclamide because it distributed for free in the government hospitals, rural 
Table 3: Prevalence of obesity among different variables of diabetic patients.

\begin{tabular}{|c|c|c|c|c|c|c|c|c|c|c|}
\hline \multirow[t]{2}{*}{ Variable } & & \multirow{2}{*}{$\begin{array}{c}\text { Total } \\
\mathbf{N}\end{array}$} & \multicolumn{2}{|c|}{ Obese } & \multicolumn{2}{|c|}{ Non-Obese } & \multirow[t]{2}{*}{$p$-value } & \multirow[t]{2}{*}{ OR } & \multicolumn{2}{|c|}{$95 \% \mathrm{Cl}$} \\
\hline & & & $\mathrm{N}$ & $\%$ & $\mathrm{~N}$ & $\%$ & & & Lower & Upper \\
\hline \multicolumn{11}{|l|}{ Sex } \\
\hline & Female & 2256 & 764 & 33.9 & 1492 & 66.1 & $<0.001$ & 2.78 & 2.39 & 3.23 \\
\hline & Male & 2005 & 312 & 15.6 & 1693 & 84.4 & Reference & & & \\
\hline \multicolumn{11}{|l|}{ Age (year) } \\
\hline & $<25$ & & 41 & 7 & 17.1 & 34 & 82.9 & 0.581 & 0.79 & 0.34 \\
\hline & $25-34$ & & 333 & 77 & 23.1 & 256 & 76.9 & 0.371 & 1.16 & 0.84 \\
\hline & $35-44$ & & 853 & 225 & 26.4 & 628 & 73.6 & 0.010 & 1.38 & 1.08 \\
\hline & $45-54$ & & 1173 & 319 & 27.2 & 854 & 72.8 & 0.002 & 1.44 & 1.14 \\
\hline & $55-64$ & & 1193 & 310 & 26.0 & 883 & 74.0 & 0.010 & 1.35 & 1.07 \\
\hline & $\geq 65$ & & 668 & 138 & 20.7 & 530 & 79.3 & Reference & & \\
\hline \multicolumn{11}{|l|}{$\begin{array}{l}\text { Age at } \\
\text { diagnosis } \\
\text { (year) }\end{array}$} \\
\hline & $<25$ & & 110 & 19 & 17.3 & 91 & 82.7 & 0.995 & 1.00 & 0.55 \\
\hline & $25-34$ & & 701 & 168 & 24.0 & 533 & 76.0 & 0.034 & 1.51 & 1.03 \\
\hline & $35-44$ & & 1347 & 354 & 26.3 & 993 & 73.7 & 0.003 & 1.70 & 1.19 \\
\hline & $45-54$ & & 1245 & 343 & 27.6 & 902 & 72.4 & 0.001 & 1.82 & 1.27 \\
\hline & $55-64$ & & 621 & 151 & 24.3 & 470 & 75.7 & 0.028 & 1.54 & 1.05 \\
\hline & $\geq 65$ & & 237 & 41 & 17.3 & 196 & 82.7 & Reference & & \\
\hline \multicolumn{11}{|l|}{$\begin{array}{l}\text { Duration of } \\
\text { DM (years) }\end{array}$} \\
\hline & $<1$ & & 1041 & 272 & 26.1 & 769 & 73.9 & 0.023 & 1.32 & 1.04 \\
\hline & $1-4.9$ & & 958 & 260 & 27.1 & 698 & 72.9 & 0.007 & 1.39 & 1.09 \\
\hline & $5-9.9$ & & 925 & 236 & 25.5 & 689 & 74.5 & 0.049 & 1.28 & 1.00 \\
\hline & $10-14.9$ & & 718 & 177 & 24.7 & 541 & 75.3 & 0.131 & 1.22 & 0.94 \\
\hline & $\geq 15$ & & 619 & 131 & 21.2 & 488 & 78.8 & Reference & & \\
\hline \multicolumn{11}{|l|}{ hba1c } \\
\hline & $<7$ & & 579 & 186 & 32.1 & 393 & 67.9 & $<0.001$ & 1.63 & 1.33 \\
\hline & $7-8.9$ & & 1092 & 308 & 28.2 & 784 & 71.8 & $<0.001$ & 1.35 & 1.15 \\
\hline & $\geq 9$ & & 2342 & 528 & 22.5 & 1814 & 77.5 & Reference & & \\
\hline \multicolumn{11}{|l|}{$\begin{array}{l}\text { Medications } \\
\text { at } \\
\text { presentation }\end{array}$} \\
\hline & Yes & & 3462 & 883 & 25.5 & 2579 & 74.5 & 0.427 & 1.08 & 0.90 \\
\hline & No & & 799 & 193 & 24.2 & 606 & 75.8 & Reference & & \\
\hline \multicolumn{11}{|l|}{$\begin{array}{l}\text { Medications } \\
\text { at } \\
\text { presentation }\end{array}$} \\
\hline & No medications & & 799 & 193 & 24.2 & 606 & 75.8 & Reference & & \\
\hline & Insulin & & 544 & 144 & 26.5 & 400 & 73.5 & 0.337 & 1.13 & 0.88 \\
\hline & 1 oral agent & & 1151 & 302 & 26.2 & 849 & 73.8 & 0.299 & 1.12 & 0.91 \\
\hline & $\geq 2$ oral agents & & 1535 & 354 & 23.1 & 1181 & 76.9 & 0.554 & 0.94 & 0.77 \\
\hline & Insulin and oral agents & & 232 & 83 & 35.8 & 149 & 64.2 & $<0.001$ & 1.75 & 1.28 \\
\hline
\end{tabular}

hospitals and in some health centers which could be a factor in poor control among many patients who decrease the dose on their own to avoid hypoglycemia. Metformin is the $3^{\text {rd }}$ most common medication among our patients, it was used as a single agent in $13 \%$ of the patients and the HBA1c in this group of patients was significantly lower than those not on medications (mean HBA1c 8.8 p-value $<0.001$ ). Insulin was used in $12.8 \%$ of our patients as a single agent with most patients uncontrolled (mean HBA1c 9.9\% p-value 0.098) when compared to patients not on medications. Mixed insulin is the most common form of insulin used because it is distributed by the ministry of health for free. The high HBAlc among these patients may be due to multiple factors as the dose is not titrated to bring the blood glucose levels down in most hospitals and most patients do not do regular glucochecks, also periodic HBA1c levels weren't done especially in rural areas and many doctors still depend on a fasting and post prandial glucose levels when treating patients. The patient is started on a dose and is given

Citation: Al-Sharafi BA, Algoby MA, Salem K (2020) Glycemic Control, Medication Use and Obesity among Patients with Type 2 Diabetes Mellitus Presenting to an Endocrinology Clinic during the War in Yemen. A Three-Year Retrospective Study. J Diab Res Ther 6(2): dx.doi. org/10.16966/2380-5544.152: dx.doi.org/10.16966/2380-5544.152 
Table 4: Difference of hba1c in DM's medications at presentation $(\mathrm{N}=4031)$.

\begin{tabular}{|l|c|c|c|c|}
\hline Variable & N & $\begin{array}{c}\text { Mean } \\
\text { HBA1c }\end{array}$ & SD & P-value \\
\hline No medication & 799 & 9.7 & 2.6 & Reference \\
\hline Sulfonylureas & 564 & 9.6 & 2.5 & 0.553 \\
\hline Metformin & 553 & 8.8 & 2.4 & $<0.001$ \\
\hline TZD & 19 & 8.8 & 2.7 & 0.151 \\
\hline DPP4 inhibitor & 13 & 9.4 & 2.3 & 0.634 \\
\hline SGLT2 inhibitor & 2 & 9.2 & 2.6 & 0.765 \\
\hline Insulin & 544 & 9.9 & 2.2 & 0.098 \\
\hline Met+sulf & 1336 & 9.9 & 2.4 & 0.105 \\
\hline Other 2 oral agents & 76 & 10.2 & 8.5 & 0.637 \\
\hline 3 oral agents & 121 & 9.4 & 2.3 & 0.171 \\
\hline 4 oral agents & 2 & 6.2 & 1.6 & 0.058 \\
\hline Oral agents+insulin & 232 & 10 & 2.2 & 0.153 \\
\hline
\end{tabular}

Table 5: Age of onset and hba1c in patients with diabetes less than one year $(\mathrm{N}=1041)$.

\begin{tabular}{|l|c|c|c|c|}
\hline \multicolumn{1}{|c|}{ Variable } & & Mean (SD) & N & $\%$ \\
\hline Age (year) & & $44.9(12.3)$ & & \\
\hline & $<25$ & & 31 & 3.0 \\
\hline & $25-34$ & & 180 & 17.3 \\
\hline & $35-44$ & & 320 & 30.7 \\
\hline & $45-54$ & & 244 & 23.4 \\
\hline & $55-64$ & & 187 & 18.0 \\
\hline hba1c & $\geq 65$ & & 79 & 7.6 \\
\hline & & $9.7(2.6)$ & & \\
\hline & $<7$ & & 182 & 18.3 \\
\hline & $7-8.9$ & & 252 & 25.4 \\
\hline & $\geq 9$ & & 560 & 56.3 \\
\hline
\end{tabular}

Table 6: Comparisons of some variables between the current and previous study.

\begin{tabular}{|l|c|c|c|c|c|c|}
\hline Variable & & \multicolumn{2}{|c|}{ Current study } & \multicolumn{2}{c|}{ Previous study } & $p$-value \\
\hline & & Mean & SD & Mean & SD & \\
\hline Age (year) & Female & 51.97 & 11.36 & 50.65 & 10.71 & 0.002 \\
\hline & Male & 50.36 & 13.33 & 50.30 & 12.47 & 0.914 \\
\hline & Total & 51.21 & 12.35 & 50.50 & 11.52 & 0.043 \\
\hline Height (m) & Female & 1.53 & 0.06 & 1.52 & 0.06 & $<0.001$ \\
\hline & Male & 1.65 & 0.07 & 1.65 & 0.07 & 1.000 \\
\hline & Total & 1.58 & 0.09 & 1.58 & 0.09 & 1.000 \\
\hline Weight $\mathbf{( k g )}$ & Female & 65.95 & 13.09 & 64.71 & 12.89 & 0.015 \\
\hline & Male & 70.13 & 13.63 & 69.23 & 12.39 & 0.105 \\
\hline & Total & 67.92 & 13.51 & 66.70 & 12.87 & 0.001 \\
\hline BMI (kg// $\left.\mathbf{m}^{\mathbf{2}}\right)$ & Female & 28.26 & 5.38 & 28.02 & 5.29 & 0.252 \\
\hline & Male & 25.80 & 4.36 & 25.42 & 3.88 & 0.030 \\
\hline & Total & 27.10 & 5.07 & 26.88 & 4.90 & 0.132 \\
\hline hba1c & Female & 9.64 & 2.46 & 9.61 & 2.50 & 0.757 \\
\hline & Male & 9.69 & 2.90 & 10.07 & 2.91 & 0.003 \\
\hline & Total & 9.67 & 2.68 & 9.81 & 2.70 & 0.073 \\
\hline
\end{tabular}

Table 7: The difference in obesity $(\mathrm{BMI} \geq 30)$ in males and females between the current and previous study.

\begin{tabular}{|l|c|c|c|c|c|c|c|}
\hline \multicolumn{1}{|c|}{ Sex } & \multicolumn{3}{c|}{ Current study } & \multicolumn{3}{c|}{ Previous study } & p-value \\
\hline & $\mathrm{N}$ & Mean & SD & N & Mean & SD & \\
\hline Male & 312 & 33.0 & 2.7 & 79 & 32.3 & 2.3 & 0.035 \\
\hline Female & 764 & 34.1 & 3.8 & 294 & 33.9 & 3.9 & 0.447 \\
\hline
\end{tabular}

a card to receive his insulin monthly and the patient can't receive a higher dose for free until the year is over and the patient needs to renew his card. Regular insulin is not always available for distribution to the patients and if prescribed many patients can't afford to buy it. Also many patients do not seek medical care with a physician until the year is over and a new prescription is required. Therapeutic inertia is common among diabetic patients either due to the patient not seeking medical help for uncontrolled diabetes or the physicians failing to adjust medications to reach proper control, both factors are common among our patients [21,22]. Basal insulin is the preferred insulin to start patients on in addition to oral agents $[20,23]$ but it is not commonly used due to limited availability in rural areas and cost. The majority of the patients were on met, sulf, a combination of both or insulin $(70.1 \%)$ and an additional $18.8 \%$ not on medications at presentation to our clinic making a total of $88.9 \%$ leaving only $11.1 \%$ on any other combination of medications and only $5.4 \%$ of the patients were on a combination of insulin and oral agents. Among the patients not on medications not all of them were newly diagnosed, the mean duration of diabetes was 1.6 years (SD 3.1).

Many factors could be contributing to the limited use of other medications and uncontrolled diabetes such as poverty (many people lost their jobs and most government employees in Sana'a and surrounding areas have not been receiving regular salaries for the last 3 years including physicians in government hospitals), unavailability of medications, decreased motivation of physicians to improve glycemic control (crowded hospitals with little resources, decreased income, increase in communicable diseases) and non-compliance of patients in using medications. It has been found that an increased workload decreases physician motivation in addition to decreased education of patients regarding the disease [24]. Unfamiliarity of primary care physicians with newer medications (indications and side effects), lack of diabetes educators, limited number of dietitians to help in the care of the patients and limited number of specialized clinics in government hospital to treat diabetic patients are additional factors. Further studies have to be done to study the different factors causing poor control and address them to improve glycemic control in Yemen. More education for primary care physicians will familiarize them with the newer guidelines for treatment of diabetes and presence of diabetes educators will improve patient compliance and adherence to medications and get better control $[25,26]$. Patients should not have to wait a whole year to receive higher doses of insulin when required. Some medications such as GLP-1 receptor agonists are not available in the country since the start of the war in 2015 and SGLT-2 inhibitors just became available at the end of 2019, basal insulins and insulin analogues are available but on a limited basis and at times are unavailable due to the embargo on the country since the start of war.

Limitations of our study is that it is a single center study. Where the patients were treated previously was not documented in the charts and there are no previous studies regarding medication use prior to the war to see if there was any difference in physician practices. More studies have to be done to address the different factors leading to poor control of diabetes. It is important that physicians are compensated for their 
work and receive more education on diabetes. A program should be started to train diabetes educators which will help many patients learn more about the disease and help reach better control.

\section{Conclusion}

Patients with type $2 \mathrm{DM}$ presenting to an endocrinology clinic during the war in Yemen showed poor control with little use of newer available medications. Many factors need to be addressed to achieve improved control of diabetes. Females were significantly more likely to be obese than males but when compared to previous prevalence of obesity in Yemeni patients with type 2 DM there was a slight increase in obesity among males with no significant increase in obesity in females.

\section{Acknowledgements}

The authors would like to thank Dr. Farouk Al-Qadasi for his assistance with the statistical analysis. Also we wish to thank Dr. Maram Al-Gunaid and Dr. Sarah Al-Hammodi for reviewing the charts.

\section{Financial Disclosure}

No funding was received for this research.

\section{Conflict of Interest}

The authors declare no conflict of interest.

\section{Informed Consent}

Informed consent was not required because of the retrospective character of the study.

\section{Authors Contributions}

BA had the initial idea for the study, designed the study and wrote the manuscript. MA helped in designing the study and writing the manuscript. KS reviewed the literature and assisted in writing the manuscript, all authors contributed to drafting the manuscript and agreed on the final draft of the paper.

\section{Data Availability}

The database of the study is available from the author on request.'

\section{References}

1. Qirbi N, Ismail SA (2017) Health system functionality in a lowincome country in the midst of conflict: the case of Yemen. Health Policy Plan 32: 911-922.

2. Al-Sharafi BA, Al-Tihami BA (2017) The effect of War on the Control of Diabetes in Patients with type 2 diabetes meillitus in Yemen: $A$ Cross-Sectional Study. Endocrinol Metab Syndr 6: 4.

3. Owolabi MO, Yaria JO, Daivadanam M, Makanjuola Al, Parker G, et al. (2018) Gaps in Guidelines for the management of Diabetes in Low-and Middle-income Versus high-income Countries-A Systematic Review. Diabetes Care 41: 1097-1105.

4. YimamAhmed M, Ejigu SH, Zeleke AZ, Hassen MY (2020) Glycemic Control, Diabetes Complications and Their Determinants among Ambulatory Diabetes Mellitus Patients in Southwest Ethiopia: A Prospective Cross-Sectional Study. Diabetes Metab Syndr Obes 13: 1089-1095.

5. Waari G, Mutai J, Gikunju J (2018) Medication adherence and factors associated with poor adherence among type 2 diabetes mellitus patients on follow-up at Kenyatta National Hospital, Kenya. Pan Afr Med J 29: 82.
6. Novo A, Jokie I (2008) Medical Audit of Diabetes Mellitus in Primary Care Setting In Bosnia and Herzegovina. Croat Med J 49: 757-762.

7. Syed Soffian SS, Ahmad SB, Shan H-K, Soelar SA, Abu Hassan MR, et al. (2019) Management and glycemic control of patients with type 2 diabetes mellitus at primary care level in Kedah, Malaysia: A statewide evaluation. PLoS One 14.

8. Mansour AA (2008) Patients' opinion on the barriers to diabetes control in areas of conflicts: The Iraqi example. Confl Health 2: 7.

9. Abuyassin B, Laher I (2015) Obesity-linked diabetes in the Arab world: a review. East Mediterr Health J 21: 420-439.

10. Al Zurba Fl, Al Garf A (1996) Prevalence of diabetes mellitus among Bahrainis attending primary health care centres. East Mediterr Health J 2: 274-282.

11. Malik M, Bakir A, Saab BA, King H (2005) Gllucose intolerance and associated factors in the multi-ethnic population of the United Arab Emirates: results of a national survey. Diabetes Res Clin Pract 69: 188-195.

12. Al-Moosa S, Allin S, Jemiai N, Al-Lawati J, Mossialos E (2006) Diabetes and urbanization in the Omani population: an analysis of national survey data. Popul Health Metr 4: 5.

13. Al-Shahrani A, Al-Khaldi Y (2013) Obesity among diabetic and hypertensive patients in Aseer region, Saudi Arabia. Saudi J Obes 1: 14-17.

14. Ghassibe-Sabbagh M, Deeb M, Salloum AK, Mouzaya F, Habar M, et al. (2014) Multivariate epidemiological analysis of type 2 DM risks in the Lebanese population. Diabetol Metabol Syndr 6: 89.

15. Yassin MM, Altibi HI, ElShanti AF (2011) Clinical and biochemical features of type 2 diabetic patients in Gaza Governorate, Gaza Strip. West Afr J Med 30: 51-56.

16. Zimmet PZ (2017) Diabetes and its drivers: the largest epidemic in human history. Clinical Diabetes and Endocrinology 3: 1.

17. Mansour AA (2009) Chronic Complications of Diabetes in Iraq: Experience from Southern Iraq. Clinical Medicine Insights: Endocrinology and Diabetes 2: 89-97.

18. Kayali M, Moussally K, Lakis C, Abrash MA, Sawan C, et al. (2019) Treating Syrian refugees with diabetes and hypertension in Shatila refugee camp, Lebanon: Medecins Sans Frontieres model of car and treatment outcomes. Confl Health13: 12.

19. Spann SJ, Nutting PA, Galliher JM, Peterson KA, Pavlik VN, et al. (2006) Management of type 2 Diabetes in the Primary Care Setting: A Practice-Based Research Network Study. Ann Fam Med 4: 23-31.

20. IDF Clinical Practice Recommendations for managing Type 2 Diabetes in Primary Care-2017.

21. Reach G, Pechtner V, Gentilella R, Corcos A, Ceriello A (2017) Clinical inertia and its impact on treatment intensification in people with type 2 diabetes mellitus. Diabet Metab 14: 501-511.

22. Khunti K, Gomes MB, Pocock S, Shestakova MV, Pintat S, et al. (2018) Therapeutic inertia in the treatment of hyperglycaemia in patients with type 2 diabetes: A systematic review. Diabetes Obes Metab 20: 427-437.

23. Standards of Medical Care in Diabetes-2020 (2020) Diabetes Care 43: S98-S110.

24. Alhyas L, Jones Nielsen JD, Dawoud D, Majeed A (2013) Factors affecting the motivation of healthcare professionals providing care to Emiratis with type 2 diabetes. JRSM Short Rep 4: 14. 
25. Ji Hong, Chen R, Huang Y, Li W, Shi C, et al. (2019) Effect of simulation education and case management on glycemic control in type 2 diabetes. Diabetes Metab Res Rev 35: e3112.

26. Spencer MS, Kieffer EC, Sinco B, Piatt G, Palmisano G, et al. (2018) Outcomes at 18 Months from a Community Health Worker and Peer Leader Diabetes Self-Management Program for Latino Adults. Diabetes Care 41: 1414-1422. 